\title{
Complications relating to accuracy of reduction of intertrochanteric fractures treated with a compressive hip screw
}

\author{
Francisco Guerra Pinto, Pedro Dantas, Rodrigo Moreira, Rosa Mamede, Luís Branco Amaral \\ Division of Orthopaedics, Curry Cabral Hospital, Lisbon - Portugal
}

\begin{abstract}
Intertrochanteric fracture is the most frequent type of fracture in the proximal femur and the compressive hip screw is one of the most popular methods of treatment. The reduction criteria for this type of fracture are ill-defined. The purpose of this study was to validate 3 reduction criteria: displacement, alignment in the anteroposterior and in the lateral plane. We reviewed a cohort of 430 intertrochanteric fractures treated with a compression hip screw. The type of fracture, quality of reduction and technical complications were noted. We observed a relationship between accuracy of reduction and the incidence of complications, even among fractures of the same severity. A displacement bigger than $4 \mathrm{~mm}$ and failure to accomplish correct alignment (a neck-shaft angle over $125^{\circ}$ and less than $20^{\circ}$ angulation on the lateral view) was considered a poor reduction and was associated with more complications.
\end{abstract}

KEY WORDS: Reduction intertrochanteric fracture, Alignment, Displacement, Complications

Accepted: December 23, 2009

\section{INTRODUCTION}

There are several surgical options for treating intertrochanteric fractures, including the compression dynamic hip screw and the cephalomedullary nail (1-3). Complications and fixation failure are related to several factors including bone quality, fracture pattern, quality of reduction, implant design and implant placement (4). Valid criteria for a correct post-operative reduction are not clear in the published literature, despite frequent reference to the distance between the fragments and the alignment (5-7).

The purpose of this study was to validate 3 reduction criteria (displacement, alignment in the anteroposterior and the lateral views) already discussed by other authors (810). We reviewed a 7 year cohort of intertrochanteric fractures treated with a compressive hip screw in an attempt to document the relationship between the fracture type, the quality of reduction and complications.

\section{MATERIAL AND METHODS}

Six hundred and thirty-eight patients with intertrochanteric fractures were treated using a compression hip screw between June 1999 and July 2006. In the same period, 103 patients were treated with a blade-plate and 74 with a short femoral nail.

We analysed the cases treated with a compressive screw retrospectively. Only cases with follow-up of at least three months were included. Four hundred and thirty patients (67.4\%) had complete clinical and radiographic data 3 months after surgery (or evidence of technical complications before this date).

We reviewed the demographic data (sex and age) and the radiographic images (pre-operative, intra-operative fluoroscopy prints, post-operative and the latest radiographs available). The radiological evaluation included the classification of the fracture $(\mathrm{AO} / \mathrm{OTA}),(11,12)$ the quality of reduction, the 


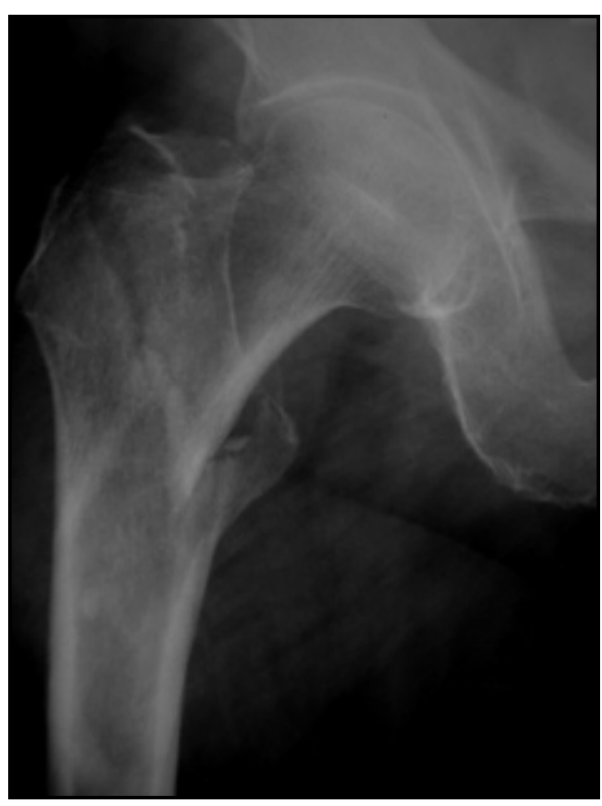

Fig. 1 - 31 A1 fracture. There is a simple fracture line without a third postero-medial fragment or a lateral cortex fracture.

existence and type of technical complications and details of any reintervention.

The quality of reduction was based on work by Sernbo, Baumgaertner and others (8-10).

The alignment achieved should be an anatomical neck-shaft angle. On the AP view we considered an angle below $125^{\circ}$ or bigger than $145^{\circ}$ as abnormal. On the lateral view we considered $20^{\circ}$ of anterior or posterior angulation as abnormal. The displacement of the fracture should be equal to or less than 4 millimetres (or inter-fragmentary displacement, in any direction). To overcome the variation in the scale amongst different radiographs, we scaled our measurements on the screw shaft diameter of $8 \mathrm{~mm}$.

We labelled a reduction as good when there was alignment (neck-shaft angle $125^{\circ}-145^{\circ}$ in the AP view and $\leq 20^{\circ}$ angulation on the lateral view) and the displacement was $4 \mathrm{~mm}$ or less. We labelled reduction acceptable when it met the criteria of a good reduction with respect to alignment or displacement, but not both. A poor reduction met neither criterion.
Technical complications were based on the descriptions by Parker and Handoll (13): intra-operative fracture of the femur, late fracture, cut-out of the implant, fixation failure / loss of reduction and breakage of the implant. We also included cases of cephalic penetration, excessive fracture collapse with shortening, and non-union.

\section{RESULTS}

Of our 430 patients 352 (81.9\%) were female and 78 (18.1\%) were male.

Most of these patients (75.3\%) were in their 80's and 90's (Tab. I). The average age was $80.8 \pm 10.0$ years.

According to the AO/OTA, 199 (46.3\%) were 31-A1 fractures (Fig. 1), 213 (49.5\%) were 31-A2 (Fig. 2) and 18 (4.2\%) were 31-A3 fractures (Fig. 3).

Overall, the quality of reduction was considered good in 249 (57.9\%) cases, acceptable in 163 (37.9\%) (Fig. 4) and poor in $18(4.2 \%)$ cases.

The quality of reduction was better in the most simple fracture patterns (Tab. II). A good quality of reduction was achieved in nearly $73 \%$ of the $31-\mathrm{A} 1$ fractures, in $44 \%$ of the $31-\mathrm{A} 2$ fractures and in $56 \%$ of the $31-\mathrm{A} 3$ fractures. The Chi-Squared Test confirmed the statistical evidence of these data, for $\mathrm{p}<0.05$.

We had 50 patients (11.6\%) with technical complications (Tab. III), including 23 cases of loss of reduction (including shaft medialisation and varus collapse, without cut-out) (Fig. 5), 16 cases of cut-out, 1 case of cephalic penetration, 3 cases of intra-operative fracture of the greater trochanter, 2 cases of breakage of the implant, 1 late subcapital fracture and 2 late fractures below the hardware. We included 2 cases of significant symptomatic collapse with jutting out $(>3 \mathrm{~cm})$ of the lag screw. In some cases with more than one related complication (for example, loss of reduction with cut-out) we considered the most serious (i.e. cut-out).

Technical complications occurred in $11.5 \%$ of male pa-

TABLE I - AGE DISTRIBUTION

\begin{tabular}{|c|c|c|c|c|c|c|}
\hline$\leq 50 y$ & $51-60 y$ & $61-70 y$ & $71-80 y$ & $81-90 y$ & $91-100 y$ & $\geq 101 y$ \\
\hline $6(1.4 \%)$ & $12(2.8 \%)$ & 37 (8.6\%) & 128 (29.8\%) & 196 (45.6\%) & 49 (11.4\%) & $2(0.4 \%)$ \\
\hline
\end{tabular}



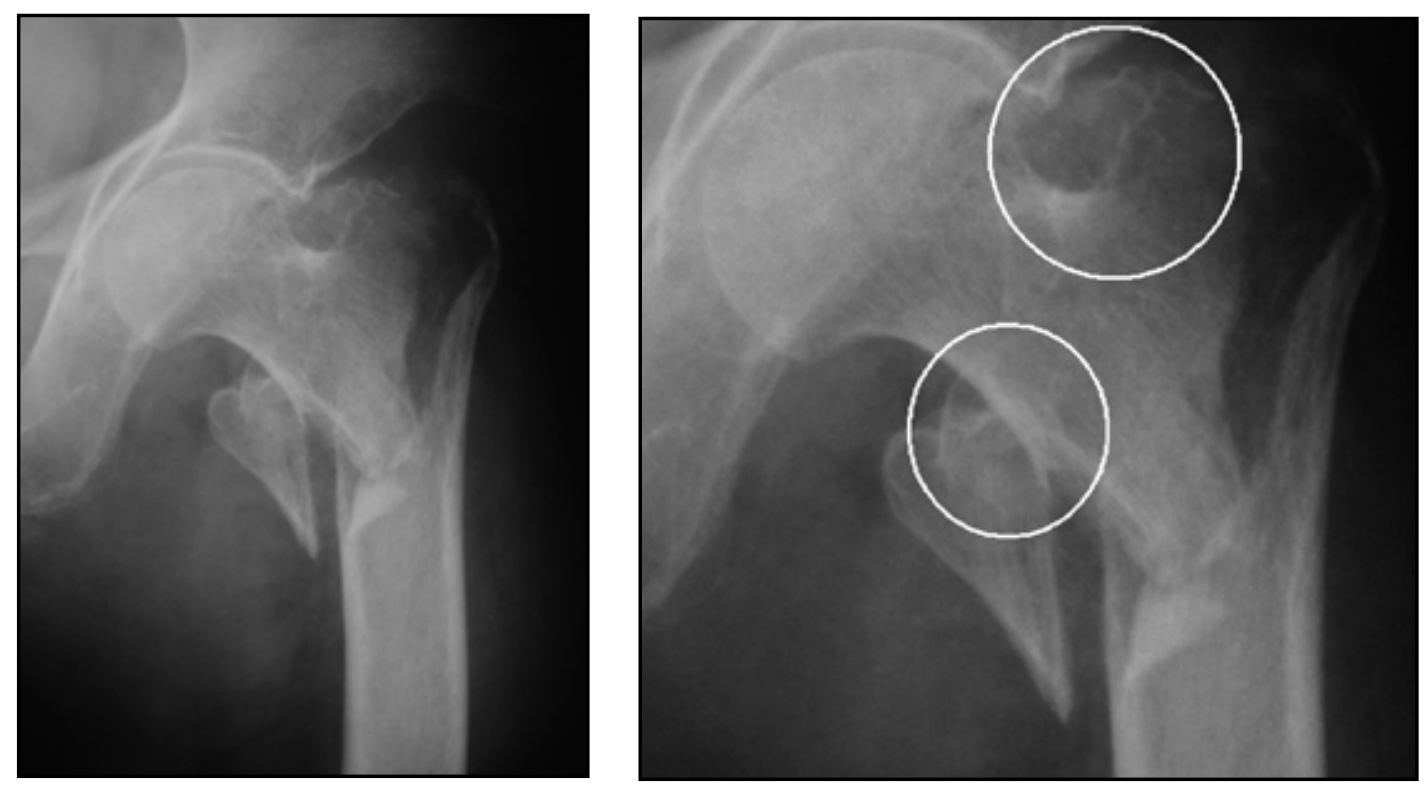

Fig. 2 - $31 A 2$ fracture. The postero-medial comminution is outlined with the white circles.
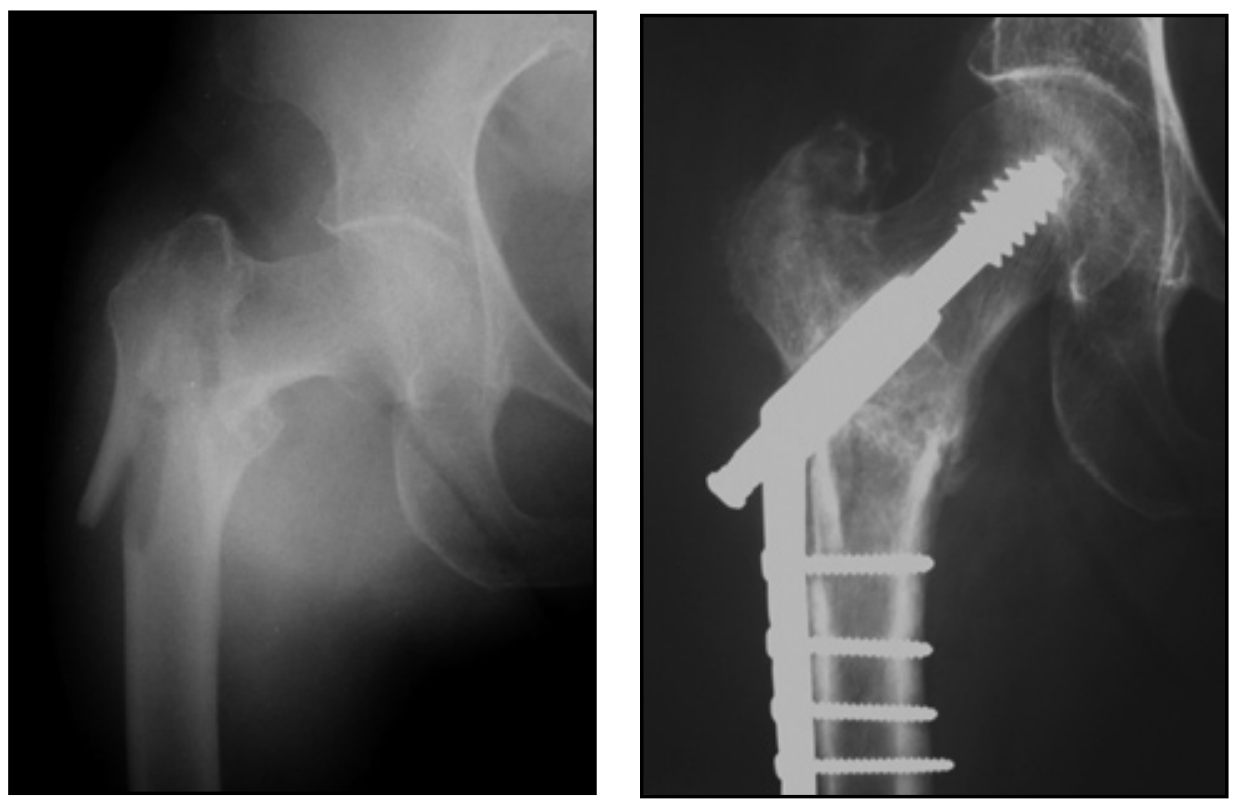

Fig. 3 - 31A3 fracture. The reverse obliquity is clearly seen on the lateral cortex. Despite the unstable pattern with a compressive hip screw the good reduction allowed an uneventful recovery.

TABLE II - GROUP OF FRACTURE AND QUALITY OF REDUCTION

\begin{tabular}{cccccccc}
\hline AO/OTA & \multicolumn{2}{c}{ Good reduction } & \multicolumn{2}{c}{ Acceptable reduction } & \multicolumn{2}{c}{ Poor reduction } & \multicolumn{2}{c}{ Total } \\
\hline $31-\mathrm{A} 1$ & 145 & $(72.9 \%)$ & 53 & $(26.6 \%)$ & 1 & $(0.5 \%)$ & 199 \\
$31-\mathrm{A} 2$ & 94 & $(44.1 \%)$ & 103 & $(48.4 \%)$ & 16 & $(7.5 \%)$ & 213 \\
$31-\mathrm{A} 3$ & 10 & $(55.5 \%)$ & 7 & $(38.9 \%)$ & 1 & $(5.5 \%)$ & 18 \\
& 249 & & 163 & & 18 & & 430 \\
\hline
\end{tabular}




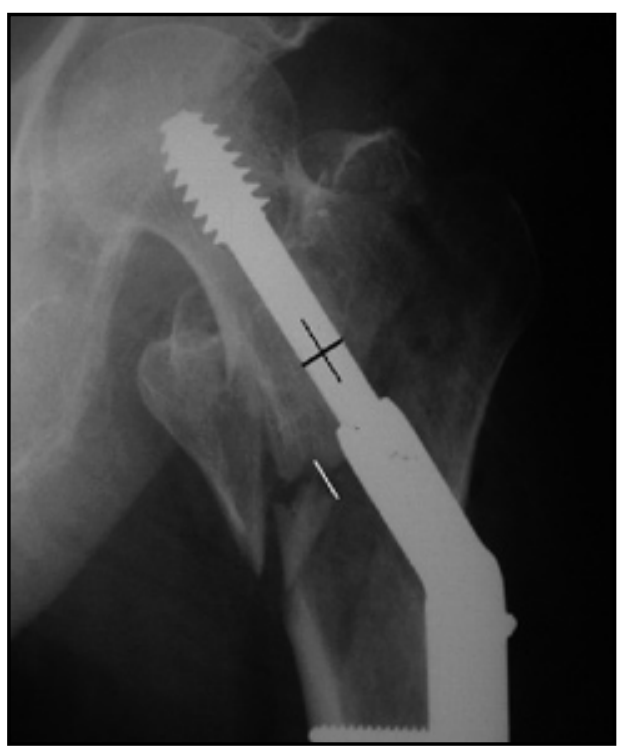

Fig. 4 - Same case as Figure 2. The gap marked with the white line is bigger than $4 \mathrm{~mm}$. This is an acceptable reduction.

TABLE III - TYPE OF TECHNICAL COMPLICATIONS IN 430 PATIENTS WITH A COMPRESSIVE HIP SCREW

Technical complications

\begin{tabular}{lc}
\hline Loss of reduction & 23 \\
Cut-out & 16 \\
Cephalic penetration & 1 \\
Intra-operative fracture & 3 \\
Breakage of the implant & 2 \\
Late fracture & 3 \\
Collapse & 2 \\
Total & 50 \\
\hline
\end{tabular}

TABLE IV - RELATION BETWEEN THE AO/OTA FRACTURE GROUP AND THE INCIDENCE OF TECHNICAL COMPLICATIONS

\begin{tabular}{lc}
\hline AO/OTA & Complications \\
\hline $31-\mathrm{A} 1$ & $15(7.5 \%)$ \\
$31-\mathrm{A} 2$ & $29(13.6 \%)$ \\
$31-\mathrm{A} 3$ & $6(33.3 \%)$ \\
Total & 50 \\
\hline
\end{tabular}

tients and in $11.7 \%$ of female patients. We did not observe any complications in the under-50's or in those aged over 101. Complications occurred in $9 \%(1 / 12)$ of patients between 51 and 60 years of age, in 16\% between 61 and 70 years of age, in $16 \%$ of patients between 71 and 80 years of age, in $11 \%$ of patients between 81 and 90 years old and in 14\% of patients between 91 and 100 years old.

Among the 23 cases with loss of reduction, 4 were classified as AO/OTA 31-A1 fractures, 16 as 31-A2 (Fig. 5) and 3 as $31-A 3$ fractures. Four patients were re-operated on, three with a compressive hip screw and one with an intramedullary nail. In this sub-group of 23 patients, two patients died in the post-operative period following the second operation.

Among the 16 patients with cut-out, 8 were $31-\mathrm{A} 1,6$ were 31-A2 and 2 were 31-A3 fractures. A reoperation was performed in eleven cases, with a compressive hip screw in one patient and with a blade plate in three cases. A hemiarthroplasty was done in five patients and a total hip replacement was performed in one. In another patient the fracture had already united with acceptable varus collapse and the hardware was removed. Four very low demand patients refused reintervention and one patient died before the second operation.

The patient with a cephalic penetration had a 31-A1 fracture, and refused further surgery.

The 3 cases of intra-operative fracture of the greater trochanter were all in the 31-A2 group. One was re-operated with a blade-plate and cerclage wiring, another with a hemiarthroplasty and the third had trochanteric fixation with screws. The first of these died two months after the reintervention.

The 2 cases of implant breakage, both in 31-A2 fractures, occurred in the distal screws. Both caused an unacceptable loss of reduction and were reoperated on with a new compressive hip screw.

There was a late subcapital fracture in a 31-A2 fracture, 2 months post-operatively, after a further fall. A total hip replacement was carried out.

Two late fractures below the implant, in a 31-A1 and a 31A2 fracture, occurred 2 weeks and 3 months after surgery respectively. Both cases required revision surgery with a compressive hip screw and a bigger side plate.

In two cases (fracture type 31-A1 and type 31-A3) of symptomatic collapse with jutting out $(>3 \mathrm{~cm})$ of the lag screw, union of the fractures was observed. 

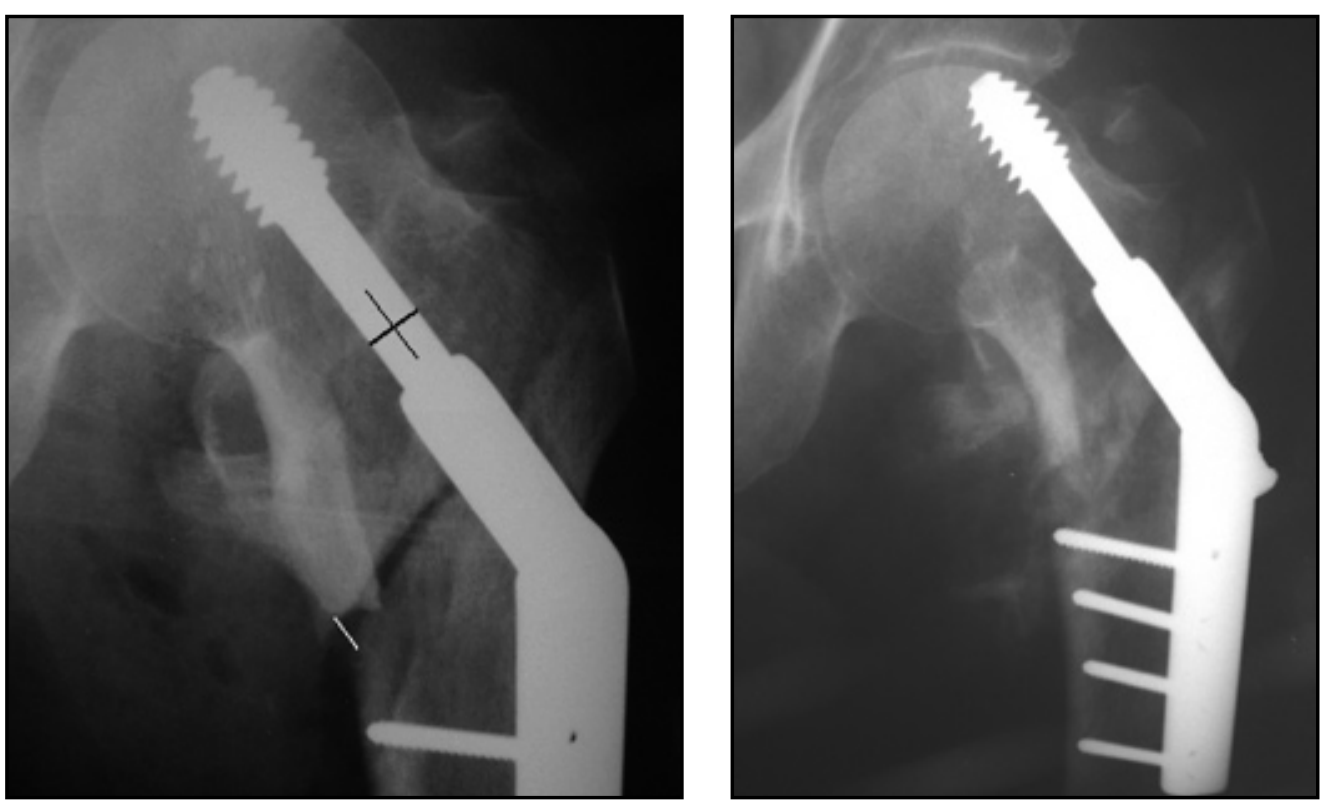

Fig. 5 - 31 A2 fracture. Because cancellous bone needs close contact to heal the gap in the medial side allowed loss of reduction. The fracture healed in that position.

\section{Incidence of technical complications}

We analysed the occurrence of technical complications according to the fracture group, according to the quality of reduction and according to the quality of reduction within each fracture group.

We noted a progressive incidence of technical complications as the fracture severity increased (Table IV). These complications occurred in $7.5 \%$ of the $31-\mathrm{A} 1$ fractures, in $13.6 \%$ of the $31-\mathrm{A} 2$ fractures and in $33.3 \%$ of the $31-\mathrm{A} 3$ fractures. The Chi-Squared Test confirms the relation between the variation in the fracture group and the variation of the incidence of technical complications $(p<0.05)$. With linear regression we obtained significant statistical meaning in this association (R Square of 0.745 ).

Among the 249 patients with a good post-operative reduction (Tab. V), $8 \%$ had technical complications. Among the 163 patients group with an acceptable reduction 12.3\% also had technical complications. These occurred in 10 out of 18 patients $(55.6 \%)$ with a poor quality of reduction. This progressive incidence of technical complications as the reduction worsens was statistically relevant $(p<0.05$, ChiSquared test).

Because the most complex fractures can be more difficult to reduce we tried to isolate these variables (Tab. VI) through the analysis of the relation between the quality of reduction and the technical complications inside each fracture group (31-A1, A2 and A3). There seems to be a progressive incidence of technical complications, inside each fracture group (AO/OTA), with the decrease of the quality of the fracture reduction (alignment and displacement). The statistical analysis with the Chi-Squared Test gives statistical evidence that the incidence of technical complications is related to the quality of reduction $(p<0.05)$ within each fracture group.

\section{DISCUSSION}

Intertrochanteric fractures of the femur have a wide range of severity. They can be a simple fractures, sometimes incomplete (type 31-A1) or fractures with great comminution and/or an unstable pattern (ex.: type 31-A3), when treated with a compressive hip screw. A recent meta-analysis (13) suggests the compressive screw as the implant of choice

TABLE V - RELATION BETWEEN THE QUALITY OF REDUCTION AND THE INCIDENCE OF TECHNICAL COMPLICATIONS

\begin{tabular}{lc}
\hline Quality of reduction & Technical complications \\
\hline Good & $8 \%(20 / 249)$ \\
Aceptable & $12 \%(20 / 163)$ \\
Poor & $56 \%(10 / 18)$ \\
\hline
\end{tabular}


for all intertrochanteric fractures, except for those with a reverse obliquity pattern.

Common causes of fixation failure are instability of the fracture, inadequate reduction (14), failure of the fixation device and the wrong location of the screw in the femoral head (5). The criteria for an acceptable reduction in intertrochanteric fractures are not yet defined and the evaluation of stability is subjective (11). Despite several references to the importance of an anatomical reduction $(6-8,15)$. We found little evidence supporting what is an acceptable reduction, especially when an anatomical one is impossible to get by closed means.

A classification system for the reduction of this type of fracture can guide the surgeon besting obtaining biomechanical stability and a good outcome.

Sernbo in 1988 compared two internal fixation methods using 3 reduction criteria to evaluate his sample (9). These have similarity with the ones considered in femoral neck fractures and include alignment and displacement, and were based on the author's opinion.

According to his description the reduction the fragments should be in "anatomical or in slight valgus, within $10^{\circ}$ " in the anteroposterior view.

We had some difficulty defining "anatomical". There is some disagreement among authors as to what constitutes an acceptable inclination of the femoral neck. From an anatomical perspective the normal neck-shaft angle is $115^{\circ}$ to $140^{\circ}(16-18)$. Other authors describe the normal neck-shaft angle as $130 \pm 7^{\circ} 11$ or $131 \pm 5^{\circ}(19,20)$. Paley considers $124^{\circ}-136^{\circ}$ as the normal neck-shaft angle when planning limb deformity correction (21).

In clinical practice it can be difficult to obtain a correct measurement of the patient's "normal" neck-shaft angle. Due to the femoral neck anteversion $\left(\approx 15^{\circ}\right)(21)$ a standard anteroposterior view of the pelvis is not a true anteroposterior view of the proximal femur, but is instead an oblique view with the same angulation as the neck anteversion plus the limb's external rotation at that moment. Unless the contralateral hip is in the appropriate internal rotation, a standard anteropstetrior view of the pelvis will be misleading.

We considered an angle below $125^{\circ}$ in the AP view as abnormal. In those patients with a post-operative neck-shaft angle between $120^{\circ}$ and $125^{\circ}$, we considered the fracture aligned when the contralateral neck-shaft angle was $130^{\circ}$ or less. We also considered an angle bigger than $145^{\circ}$ as non-aligned. This never occurred in our study. Theoretically there is a biomechanical benefit from a valgus reduction especially in patients with extensive internal comminution $(3,5,15)$, as long as this is within the capacity of the fixation device to allow compression (22).

On the lateral radiograph, Sernbo aimed for less than $20^{\circ}$ of anterior or posterior angulation. As a correct lateral radiograph of a broken proximal femur might be difficult to obtain there is a tendency to evaluate posterior angulation

TABLE VI - TECHNICAL COMPLICATIONS ACCORDING TO THE QUALITY OF REDUCTION IN EACH FRACTURE GROUP

\begin{tabular}{|c|c|c|c|}
\hline АО/ОТА & Quality of reduction & Technical complications & Total \\
\hline \multirow{3}{*}{$31-\mathrm{A} 1$} & Good & $8 \%(12 / 145)$ & 145 \\
\hline & Acceptable & $4 \%(2 / 53)$ & 53 \\
\hline & Poor & $100 \%(1 / 1)$ & 1 \\
\hline \multirow{3}{*}{$31-A 2$} & Good & $7 \%(7 / 94)$ & 94 \\
\hline & Acceptable & $14 \%(14 / 103)$ & 103 \\
\hline & Poor & $50 \%(8 / 16)$ & 16 \\
\hline \multirow{3}{*}{ 31-A3 } & Good & $10 \%(1 / 10)$ & 10 \\
\hline & Acceptable & $57 \%(4 / 7)$ & 7 \\
\hline & Poor & $100 \%(1 / 1)$ & 1 \\
\hline
\end{tabular}


as "anatomical". On the reduction table the fluoroscopy beam should first adjust to the femoral neck anteversion with a postero-anterior tilt $\left(\approx 15^{\circ}\right)$ that show the femoral shaft in line with the neck.

In relation to fracture displacement. Sernbo considered a separation of $5 \mathrm{~mm}$ to be abnormal. For practical reasons related to the size of the screw shaft $(8 \mathrm{~mm})$ we considered there was displacement when there was a gap or translation in any direction of more than $4 \mathrm{~mm}$.

Baumgaertner (8) and later Subramanian (10) also based their reduction analysis on Sernbo's criteria, with an interesting additional contribution, labelling the quality of reduction as good if the alignment was "normal" with a maximum of $20^{\circ}$ on lateral and $4 \mathrm{~mm}$ or less of displacement, acceptable if the reduction met the criteria of a good reduction according to alignment or displacement, but not both. A poor reduction met neither. We used this system to evaluate our sample. The aim of internal fixation with a compressive screw is stable fixation, so we believe that the analysis of the technical complications is a valid method of evaluation of the effects of the quality of reduction.

Our main limitation is the retrospective nature of this study with a high rate of absenteeism (32.6\%) before 3 months post-operative follow-up, or incomplete clinical data. Several authors have used 3 months as an end point because this is the time expected for this type of fracture to heal, most of the mechanical complications occur in that period and a longer minimum follow up would exclude many patients who die $(8,15,23-25)$. On the other hand several patients who missed their early follow-up consultations returned to our hospital when complications occurred.

Despite the importance of Tip-Apex-Distance it was not our purpose to evaluate the position of the implant, rather the quality of fracture reduction according to the referred criteria. The Tip-Apex-Distance is a predictor of the cutout of the implant and not for other technical complications $(7,8,26)$.

We registered an incidence of technical complications of $11.6 \%$. These values are in accordance with published data, where complications ranged from 4 to $20 \%$ depending on the complexity of the fracture $(3,8)$. Eighty-one percent of our patients were females and we did not find any differences in the incidence of technical complications between genders. Nearly $75 \%$ of our patients were in their 80 's and 90's. The incidence of complications was relatively constant in patients after their 70's. This suggests that if the patient has an intertrochanteric fracture the bone quality is already compromised and further fragility (leading to a technical complication) is less influenced by age. In our sample $50 \%$ of the fractures were in the 31-A2 group (with a third fragment of variable characteristics) and only $4.2 \%$ were in the 31-A3 group (with reverse obliquity pattern). This is consistent with other works that describe this pattern as less common, accounting for about $5 \%$ of all intertrochanteric and subtrochanteric fracture (6).

The incidence of technical complications increased with the complexity of the fracture $(p<0.05)$, especially in those with reverse obliquity (31-A3). This may be due to occasional failure to recognise reverse obliquity or excessive use of this implant. Load-sharing implants can be useful in reverse-obliquity fractures and several authors consider that the compressive screw is not the ideal device in this situation $(3,6,26)$.

Our results showed a better reduction in the most simple fractures $(p<0.05)$ and an incidence of technical complications inversely proportional to the quality of reduction. More importantly, we found that between fractures of the same severity (according to the AO/OTA classification) there is a higher incidence of technical complications in the fractures with o poorer reduction. In the $31 \mathrm{~A} 2$ group we found $7 \%$ complications with a good reduction, $14 \%$ with an acceptable reduction and $50 \%$ complications with a poor reduction. This data has statistical significance $(p<0.05)$, and justifies the validation of these parameters of reduction as a predictive factor for the incidence of technical complications in intertrochanteric fractures treated with a compression screw.

Ethical Board Review Statement: Approved by the Institutional Board Review.

No funds were received in support of this study.

No benefits in any form have been received or will be received from a commercial party related directly or indirectly to the subject of this article.

Address for correspondence:

Francisco Guerra Pinto

Hospital Curry Cabral

Rua de Beneficência, 8

Lisboa 1069-166, Portugal

fguerrapinto@gmail.com 


\section{REFERENCES}

1. Adams Cl, Robinson CM, Court-Brown CM, McQueen MM. Prospective randomized controlled trial of an intramedullary nail versus dynamic screw and plate for intertrochanteric fractures of the femur. J Orthop Trauma 2001; 15: 394-400.

2. Aros B, Tosteson AN, Gottlieb DJ, Koval KJ. Is a sliding hip screw or im nail the preferred implant for intertrochanteric fracture fixation? Clin Orthop Relat Res 2008; 466: 2827-32.

3. Bucholz RW, Heckman JD, Court-Brown C. Rockwood and Green's Fractures in Adults. 6th ed. Philadelphia: Lippincott Williams \& Wilkins, 2006.

4. Neuman R. Intertrochanteric fractures. In: Brown DE, Randall D, eds. Neumann: Orthopedic Secrets. 3rd ed. Philadelphia: Hanley \& Belfus 2004; 298-300.

5. Davis TR, Sher JL, Horsman A, Simpson M, Porter BB, Checketts RG. Intertrochanteric femoral fractures: mechanical failure after internal fixation. J Bone Joint Surg Br 1990; 72: 26-31.

6. Haidukewych GJ, Israel TA, Berry DJ. Reverse obliquity fractures of the intertrochanteric region of the femur. J Bone Joint Surg Am 2001 83: 643-50.

7. Palm H, Jacobsen S, Sonne-Holm S, Gebuhr P; Hip Fracture Study Group. Integrity of the lateral femoral wall in intertrochanteric hip fractures: an important predictor of a reoperation. J Bone Joint Surg Am 2007; 89: 470-5.

8. Baumgaertner M, Solberg B. Awareness of Tip-Apex Distance reduces failure of fixation of trochanteric fractures of the hip. J Bone Joint Surg Am 1997; 79: 969-71.

9. Sernbo I, Johnell O, Gentz CF, Nilsson JA. Unstable intertrochanteric fractures of the hip. Treatment with Ender pins compared with a compression hip-screw. J Bone Joint Surg Am 1988; 70: 1297-303.

10. Subramanian KN, Puranik G. Radiographic assessment of dynamic hip screw fixation. J Bone Joint Surg Br 2006; 88 (Suppl I): 70.

11. Fung W, Jönsson A, Bühren V, Bhandari M. Classifying intertrochanteric fractures of the proximal femur: does experience matter? Med Princ Pract 2007; 16: 198-202.

12. Orthopaedic Trauma Association Committee for Coding and Classification. Fracture and dislocation compendium. J Orthop Trauma 1996; 10 (Suppl 1): 1-154.

13. Parker MJ, Handoll HH. Gamma and other cephalocondylic intramedullary nails versus extramedullary implants for extracapsular hip fractures in adults. Cochrane Database Syst Rev 2005; 4: CD000093.

14. Oger P, Katz V, Lecorre N, Beaufils P. Fracture of the great trochanter treated by dynamic hip screw plate: measure of impaction according to fracture type. Rev Chir Orthop Reparatrice Appar Mot 1998; 84: 539-45.

15. Laros GS, Moore JF. Complications of fixation in intertrochanteric fractures. Clin Orthop Relat Res 1974; 101: 110-9.

16. Netter F. The Ciba Collection of Medical Illustrations. Vol. 8, Part I-A. Teterboro: Ciba Geigy 1993; 92.

17. Rouviere H, Delmas A. Anatomie Humaine - Descriptive, topographique et fonctionnelle. 13th ed. Paris: Masson 1996.

18. Testut Latarjet. Human anatomy. Paris: Masson 1983: I-395.

19. Craveiro Lopes N, Pais de Vasconcelos F, Salis Amaral J. Goniometria da anca normal, estudo radiográfico na criança Portuguesa. Rev Port Ortop Traum 1989: 15P IB, 1: 11-24.

20. Koval KJ, Zuckerman JD. Handbook of Fractures. 3rd ed. Philadelphia: Lippincott Williams \& Wilkins 2006.

21. Paley D, Herzenberg JE. Principles of Deformity Correction. Berlin: Springer-Verlag 2002.

22. Chang WS, Zuckerman JD, Kummer FJ, Frankel VH. Biomechanical evaluation of anatomic reduction versus medial displacement osteotomy in unstable intertrochanteric fractures. Clin Orthop Relat Res 1987; 225: 141-6.

23. Larsson S, Friberg S, Hansson L. Trochanteric fractures. Mobility, complications and mortality in 607 cases treated with the sliding-screw technique. Clin Orthop Relat Res 1990; 259: 130-9.

24. Mainds CC, Newman RJ. Implant failures in patients with proximal fractures of the femur treated with a sliding screw device. Injury 1989; 20: 98-109.

25. Rao JP, Banzon MT, Weiss AB Rayhack J. Treatment of unstable intertrochanteric fractures with anatomic reduction and compression hip screw fixation. Clin Orthop Relat Res 1983; 175: 65-71.

26. Sadowski C, Lubbeke A, Saudan M, Riand N, Stern R, Hoffmeyer P. Treatment of reverse oblique and transverse intertrochanteric fractures with use of an intramedullary nail or a $95^{\circ}$ screw-plate: a prospective, randomized study. J Bone Joint Surg Am 2002; 84: 372-81. 
Copyright of Hip International is the property of Wichtig Editore and its content may not be copied or emailed to multiple sites or posted to a listserv without the copyright holder's express written permission. However, users may print, download, or email articles for individual use. 